\title{
The Role of Trust towards the Adoption of Mobile Services in China: An Empirical Study
}

\author{
Shang $\mathrm{Gao}^{1,2, *}$ and Yuhao Yang ${ }^{2}$ \\ ${ }^{1}$ Department of Computer and Information Science, \\ Norwegian University of Science and Technology, Norway \\ shanggao@idi.ntnu.no \\ ${ }^{2}$ School of Business Administration, \\ Zhongnan University of Economics and Law, Wuhan, China \\ vincentyoo@foxmail.com
}

\begin{abstract}
This research aims to study the role of trust towards the adoption of mobile services in China. This study examined users' adoption of general mobile services by extending TAM with additional trust-related constructs. Based on the literature review from previous research, a research model with 10 research hypotheses is proposed in the study. This research model is empirically evaluated using survey data collected from a sample of 373 subjects. Seven research hypotheses are positively significant supported, while three research hypotheses are rejected in this study. The results indicate that both perceived reputation and perceived structural assurance directly affects the consumers' trust in mobile services. However, perceived environment risk does not have positive effect on consumers' trust in mobile services. Another interesting finding is that consumers' trust in mobile services does not have direct positive effect on users' intention to use mobile services.
\end{abstract}

Keywords: Mobile Services, Trust, Technology Acceptance Model, Technology Adoption.

\section{$1 \quad$ Introduction}

Along with the popularity of mobile devices and advances in wireless technology, mobile services have become more and more prevalent. Despite the rapid global diffusion of mobile devices, some mobile services have experienced much slower uptake from consumers [17]. A mobile service is a term used to describe software that runs on a mobile device. Mobile services are designed to educate, entertain, and assist users in their daily lives.

While there has been an increasing availability of mobile services, limited attention has been given to user adoption of mobile services, particularly with newly developed advanced mobile services (e.g., advanced mobile services). Prevalence of mobile services depends not only on technology advancement, but also on user adoption. Most research about the adoption of mobile services was mainly based on the

* Corresponding author.

H. Li et al. (Eds.): I3E 2014, IFIP AICT 445, pp. 46-57, 2014.

(C) IFIP International Federation for Information Processing 2014 
technology acceptance model (TAM) (e.g.,[9, 19, 28, 38] [21]). Some previous research (e.g., $[10,18])$ indicated that traditional adoption theories (e.g., TAM) failed to explain the adoption of mobile services. It is believed that current research has some limitations in explaining consumers' trust in mobile services and their feelings attached to using them. Therefore, we believe that there is a need to include the trust element into the mobile services adoption research. The problem that we want to address in this research is to investigate the role of trust towards the adoption of mobile services in terms of a research model.

Based on analysis of prior literature on technology diffusion and trust, a research model is developed to investigate the adoption of mobile services. To operationalize the research model, a measurement instrument is used to measure each of the constructs. The objective of this paper is to empirically examine how well the proposed research model is able to explain mobile services adoption. The research model is analyzed using Partial Least Squares (PLS) analysis.

The remainder of this paper is organized as follows: the literature review is provided in Section 2. The research model and hypotheses are presented in Section 3. The method and process of our empirical study are described in Section 4. This is followed by a discussion of the findings and limitations of this study in Section 5 . Section 6 concludes this research and suggests directions for future research.

\section{$2 \quad$ Literature Review}

The literature about technology adoption and trust is discussed in this section.

\subsection{Technology Adoption Research}

An important and long-standing research question in information systems research is how we can accurately explain user adoption of information systems [13]. Several models have been developed to test the users' attitude and intention to adopt new technologies or information systems. These models include the Technology Acceptance Model (TAM) [11], Theory of Planned Behavior (TPB) [1], Innovation Diffusion Theory (IDT) [33], Unified Theory of Acceptance and Use of Technology (UTAUT) [35]. Among the different models that have been proposed, TAM, which is the extension of the Theory of Reasoned Action (TRA) [15], appears to be the most widely accepted model. TAM focus on the perceived usefulness (PU) and perceived ease of use (PEOU) of a system and has been tested in some domains of E-business and proved to be quite reliable to predict user acceptance of some new information technologies, such as intranet [26], electronic commerce [32], and online shopping [22].

However, TAM's limitations relative to extensibility and explanation power have been noted [6]. Many researchers have suggested that TAM needs to be extended with additional variables to provide a stronger model [27]. Some researchers have also indicated that the major constructs of TAM cannot fully reflect the specific influences of technological and usage-context factors that may alter users' acceptance [31]. Therefore, PU and PEOU may not fully explain people's intention to adopt mobile services. We believe that TAM has limitations when investigating users' adoption of mobile services, which is also confirmed by prior research work in [37]. Moreover, 
although UTAUT unifies more factors and consolidates the functions of the technology acceptance model with the constructs of eight prominent models in IS adoption research, this increases the complexity, so that it is more complicated to test its applicability. While the acceptance and adoption of IT services has been one of the most prevailing IS research topics (e.g.,[12]), the pervasiveness of mobile services raises new questions in exploring the adoption of mobiles services, such as what are the key factors driving the adoption of mobile services, and how do usage context affect users' adoption of mobile services.

All the findings above motivate the development of a research model, which is described in next section.

\subsection{The Role of Trust in Mobile Services}

Trust is a crucial enabling factor in relations where there is uncertainty, interdependence, risk, and fear of opportunism [29]. For example, because of the absence of proven guarantees that the mobile services providers will not engage in harmful opportunistic behaviors, such as privacy violations and unauthorized use of credit card information, some users generally stay away from mobile services providers they do not trust.

In the domain of mobile services, trust can be defined as a user's belief or faith in the degree to which a specific service can be regarded to have no security and privacy threats [16]. In other words, trust means believing in mobile services now with an expectation that it will be risk free and you will be getting intangible benefits in certain ways at an unspecific time in the future. For mobile services providers, cultivating users' trust is a time-consuming process. Trust is hard to gain, but easy to lose.

Several factors can influence users' trust in mobile services. First, many users are not familiar with mobile services and mobile technology. Second, unfamiliarity with mobile services providers may make users' perception on the activities involved in mobile services as risky. For example, the lack of physical presentation of the service providers and the inability to feel and inspect the desired real products in a mobile transaction may make users feel vulnerable. Third, mobile services are also confronted with other challenges (e.g., privacy and security issues). Most users are concerned about the security of mobile services and mobile services providers' ability to protect unauthorized access to personal information. As indicated in [25], security and privacy issues are critical to the success of consumers' trust building in Internet shopping. We believe that this principle can apply to mobile services as well. Compared to traditional electronic services, users tend to perceive mobile services as riskier in nature and are more reluctant to adopt them. Fourth, corporate branding and reputation could be used to engender trust in mobile services. Last but not least, legislations and governmental policies on mobile services may also affect users' trust in mobile services.

\subsection{Trust in Technology Adoption Research}

Trust is defined as the willingness of a party to be vulnerable to the actions of another party based on the expectation that the latter one will perform particular actions [29]. After having identified the concept of trust as a key success factor in e-commerce [30], it makes trust become a much concerned forefront direction in the area of 
acceptance research. Bélanger explored trust in e-government services [5] and Gefen et al. studied the role of trust in online shopping [23]. Further, Watzdorf et al. found that the impact of trust on intention to use is insignificant in mobile emergency applications [36]. Last but not least, Chandra illustrated that building sufficient trust in mobile payment system is imperative for its adoption [8]. The difference in results probably attributes to different samples and objects. In this research, we would like to further explore the importance of trust towards mobile services adoption in China.

\section{$3 \quad$ Research Model and Hypotheses}

This study examines the acceptance of general mobile services in China. The proposed research model (see Figure 1) is an extension of TAM. In addition to perceived ease of use and perceived usefulness, the model includes trust related elements as additional factors to study the relating to user adoption of mobile services.

This study is based on a model [8] which focused on consumers' adoption of Mobile payment. Chandra's model is an extension of TAM model, and the model included the perceived usefulness (PU), perceived ease of use (PEOU), adoption intention of M-Payment system (AI). In addition to that the model indicated a positive influence of PU on AI and PEOU on PU, the influence of PEOU on AI is insignificant. In our research, we still want to confirm the influence of PEOU on AI as we change the research target into Chinese and research subject into mobile services, thus we formulate the following research hypotheses.

H1a: The perceived usefulness has a positive impact on the intention to use mobile services.

$\mathrm{H} 1 \mathrm{~b}$ : The perceived ease of use has a positive impact on the intention to use mobile services.

H1c: The perceived ease of use has a positive impact on the perceived usefulness.

As proposed in [8], the two dimensions of consumer trust are trust in mobile service provider and trust in technology facilitated by mobile service provider characteristics and mobile technology characteristics respectively. Perceived reputation $(\mathrm{PR})$ of the mobile services provider is identified a major category of trust in mobile services provider. Perceived environment risk (PER) and perceived structural assurance (PSA) are identified another two categories of trust in technology facilitated. Then, we modulate these three variables to our research model.

Perceived reputation (PR): The extent to which consumers believe in the mobile services provider's competency, honesty, and benevolence [14].

Perceived environment risk (PER): Security-related risks faced by consumers while using mobile services, including privacy risk, financial risk [2].

Perceived structural assurance (PSA): The institutional environment (here mobile technology including the mobile Internet and mobile platform) that all structures like guarantees, regulations, and promises are operational for safe, secure, and reliable services [39].

Hence, we formulate the following hypotheses.

$\mathrm{H} 2$ : Perceived reputation of the mobile services provider has a positive impact on the level of consumer trust in mobile services. 
H3a: Perceived environment risk has a negative impact on the level of consumer trust in mobile services.

$\mathrm{H} 3 \mathrm{~b}$ : Perceived structural assurance has a positive impact on the level of consumer trust in mobile services.

$\mathrm{H} 3 \mathrm{c}$ : Perceived structural assurance has a negative impact on the Perceived environment risk in mobile services.

H4a: Consume trust in mobile services has a positive impact on the perceived usefulness of mobile services.

$\mathrm{H} 4 \mathrm{~b}$ : Consume trust in mobile services has a positive impact on the perceived ease of use of mobile services.

$\mathrm{H} 4 \mathrm{c}$ : Consume trust in mobile services has a positive impact on the intention to use mobile services.

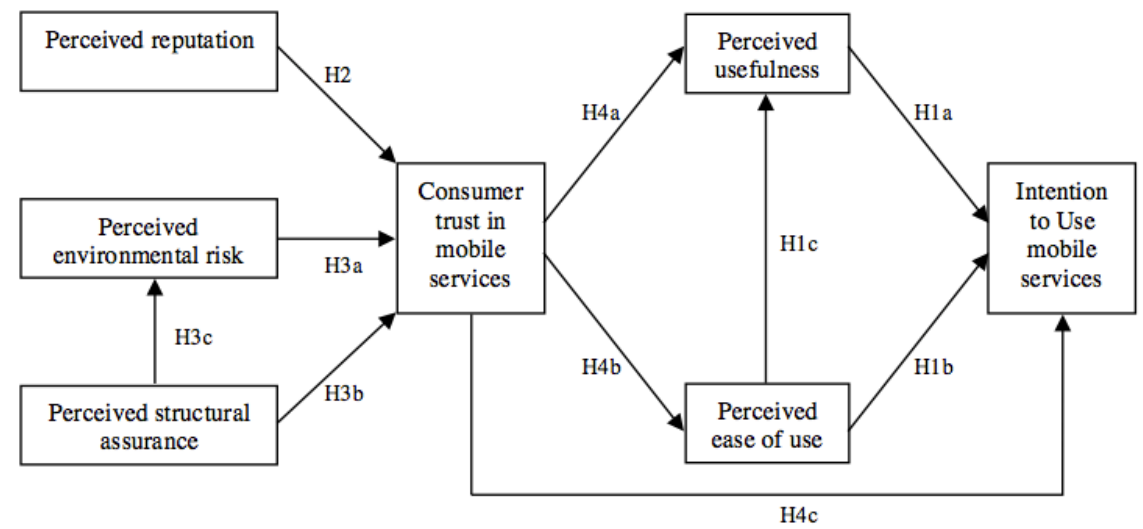

Fig. 1. Research Model

\section{$4 \quad$ An Empirical Study with the Research Model}

In this research, the research model was examined through the use of general mobile services in China.

\subsection{Mobile Commerce in China}

According to the report from the Chinese Ministry of Information Industry, the number of mobile phone subscribers in China exceeded 1 billion in March 2012 as more Chinese people began to consider mobile phones as an everyday necessity. China has the largest mobile phone market in the world. However, the mainstream usage of mobile phones in China focuses on phone calls, SMS, instant messaging services, contact services, and purchasing ring tongs [20]. Social networking services on mobile devices are becoming more and more popular in young generation in China. However, not many researches are focused on the adoption of mobile services in China. Therefore, we believe that it is still worth to develop a research model to measure the adoption of mobile services in China. 


\subsection{Instrument Development}

The validated instrument items [2, 39] [11, 18] [12] from previous research were used as the foundation to create the instrument for this study. Developed from the literature, the measurement questionnaire consisted of 24 items. In order to ensure that the instrument better fit this empirical study, some minor words changes were made to ensure easy interpretation and comprehension of the questions. A seven point Likert scale, with 1 being the negative end of the scale (strongly disagree) and 7 being the positive end of the scale (strongly agree), was used to examine participants' responses to all items in this part.

\subsection{Samples}

The data for this study were collected through self-administered questionnaires by inhabitants of the biggest city in the central part of China. The survey was distributed in terms of paper-based questionnaires individually from January 1 st 2014 to March 15, 2014. 435 completed questionnaires were collected, among which 373 of them were valid questionnaires (i.e., valid respondent rate 85.7\%). Among the participants, $66.2 \%$ of the participants used Android mobile devices, and $22.3 \%$ of the participants used iPhones. $41 \%$ of the participants were male, and $59 \%$ were female. Moreover, $52.1 \%$ of the participants were below 22 years old.

\subsection{Measurement Model}

To test the reliability and validity of each construct in the mobile service acceptance model, the Internal Consistency of Reliability (ICR) of each construct was tested with Cronbach's Alpha coefficient. For the purposes of testing the research hypotheses, data were analyzed using the structural equation modeling (SEM).

In this study, we examined goodness-of-fit of the measurement model by using six widely-used fit indices: the chi-square/degrees of freedom (x2/df), the goodness-of-fit index (GFI), the adjusted goodness-of-fit index (AGFI), the comparative fit index (CFI), the normed fit index (NFI), and the root mean square error of approximation (RMSEA). The fitness measures are shown in Table 1.

Table 1 shows that all the fitness measures are within acceptable range. Therefore, we consider the measurement model is acceptable, and the measures indicate that the model fit the data.

Convergent validity was assessed through composite reliability (CR) and the average variance extracted (AVE). Bagozzi and Yi [4] proposed the following three measurement criteria: factor loadings for all items should exceed 0.5 , the CR should exceed 0.7, and the AVE of each construct should exceed 0.5. As shown in Table 2, all constructs are in acceptable ranges except the construct perceived environmental risk (PER). Further, the Cronbach's Alpha values range from 0.732 to 0.887 . All the constructs are above 0.700. Consequently, the scales are deemed acceptable to continue. As for discriminant validity, the variances extracted by the constructs are more than the squared correlations among variables. 
Table 1. Fit indices for the measurement model

\begin{tabular}{llll}
\hline Measures & $\begin{array}{l}\text { Recommended } \\
\text { Criteria }\end{array}$ & $\begin{array}{l}\text { Measurement } \\
\text { Model }\end{array}$ & $\begin{array}{l}\text { Suggested by } \\
\text { Authors }\end{array}$ \\
\hline Chi-square/d.f. & $<3.0$ & 3.266 & Hayduk (1988) [24] \\
GFI & $>0.9$ & 0.844 & Scott (1995) [34] \\
AGFI & $>0.8$ & 0.807 & Scott (1995) [34] \\
CFI & $>0.9$ & 0.893 & Bagozzi and Yi (1988)[3] \\
NFI & $>0.9$ & 0.853 & Bentler (1990) [7] \\
RMESA & $<0.08$ & 0.078 & Bagozzi and Yi (1988)[3]
\end{tabular}

Table 2. Factor loadings, composite reliability, and AVE for each construct

\begin{tabular}{|c|c|c|c|c|c|}
\hline Construct & Item & $\begin{array}{l}\text { Factor } \\
\text { Loading }\end{array}$ & $\begin{array}{l}\text { Composite } \\
\text { Reliability } \\
\end{array}$ & AVE & $\begin{array}{l}\text { Cronbach's } \\
\text { Alpha }\end{array}$ \\
\hline \multirow[t]{3}{*}{ PR } & PR1 & 0.78 & 0.905 & 0.761 & 0.843 \\
\hline & PR2 & 0.85 & & & \\
\hline & PR3 & 0.77 & & & \\
\hline \multirow[t]{3}{*}{ PER } & PER1 & 0.64 & 0.036 & 0.218 & 0.732 \\
\hline & PER2 & 0.94 & & & \\
\hline & PER3 & 0.53 & & & \\
\hline \multirow[t]{3}{*}{ PSA } & PSA1 & 0.82 & 0.901 & 0.752 & 0.832 \\
\hline & PSA2 & 0.75 & & & \\
\hline & PSA3 & 0.80 & & & \\
\hline \multirow{4}{*}{ Trust (TU) } & TU1 & 0.84 & 0.912 & 0.725 & 0.868 \\
\hline & TU2 & 0.87 & & & \\
\hline & TU3 & 0.88 & & & \\
\hline & TU4 & 0.53 & & & \\
\hline \multirow[t]{3}{*}{ PU } & PU1 & 0.60 & 0.881 & 0.713 & 0.793 \\
\hline & PU2 & 0.83 & & & \\
\hline & PU3 & 0.84 & & & \\
\hline \multirow[t]{5}{*}{ PEOU } & PEOU1 & 0.75 & 0.917 & 0.689 & 0.887 \\
\hline & PEOU2 & 0.75 & & & \\
\hline & PEOU3 & 0.76 & & & \\
\hline & PEOU4 & 0.80 & & & \\
\hline & PEOU5 & 0.83 & & & \\
\hline \multirow{3}{*}{$\begin{array}{l}\text { Intention } \\
\text { use (IU) }\end{array}$} & IU1 & 0.80 & 0.871 & 0.694 & 0.770 \\
\hline & IU2 & 0.81 & & & \\
\hline & IU3 & 0.60 & & & \\
\hline
\end{tabular}




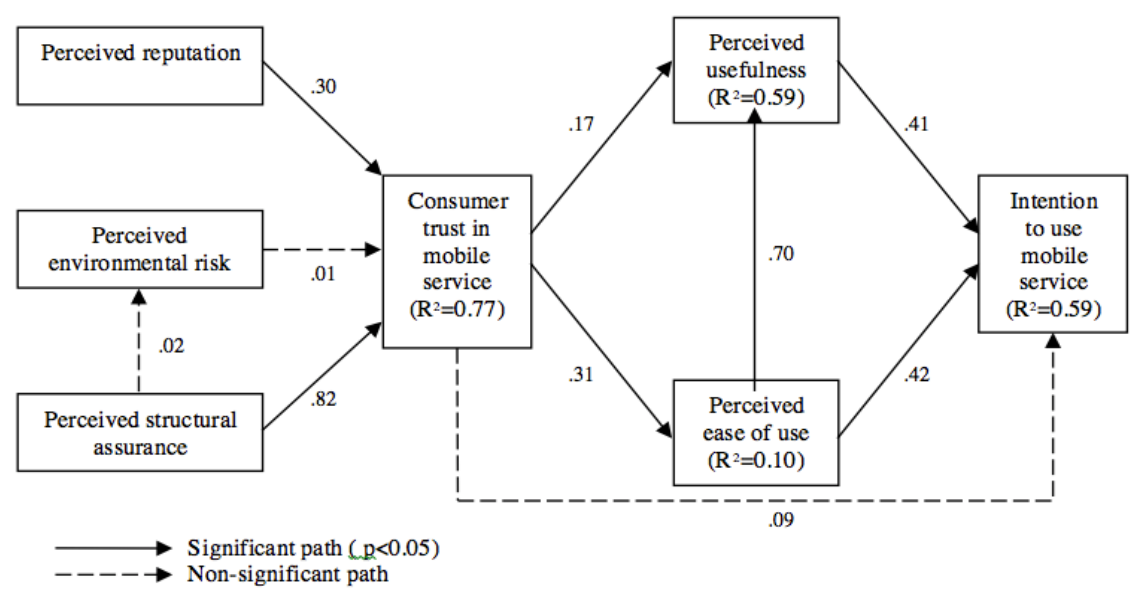

Fig. 2. Mobile services Acceptance Research Model—Results

Table 3. Test of hypotheses based on path coefficient

\begin{tabular}{|c|c|c|}
\hline Hypothesis & $\begin{array}{l}\text { Path } \\
\text { Coefficient }\end{array}$ & $\begin{array}{l}\text { Hypothesis } \\
\text { Result }\end{array}$ \\
\hline $\begin{array}{l}\text { H1a: The perceived usefulness has a positive impact on } \\
\text { the intention to use mobile services. }\end{array}$ & $0.47 * * *$ & Supported \\
\hline $\begin{array}{l}\text { H1b: The perceived ease of use has a positive impact on } \\
\text { the intention to use mobile services. }\end{array}$ & $0.44 * * *$ & Supported \\
\hline $\begin{array}{l}\text { H1c: The perceived ease of use has a positive impact on } \\
\text { the perceived usefulness. }\end{array}$ & $0.63 * * *$ & Supported \\
\hline $\begin{array}{l}\mathrm{H} 2 \text { : Perceived reputation of the mobile services provider } \\
\text { has a positive impact on the level of consumer trust in } \\
\text { mobile services. }\end{array}$ & $0.26 * * *$ & Supported \\
\hline $\begin{array}{l}\text { H3a: Perceived environment risk has a negative impact on } \\
\text { the level of consumer trust in mobile services. }\end{array}$ & 0.01 & Rejected \\
\hline $\begin{array}{l}\text { H3b: Perceived structural assurance has a positive impact } \\
\text { on the level of consumer trust in mobile services. }\end{array}$ & $0.73 * * *$ & Supported \\
\hline $\begin{array}{l}\text { H3c: Perceived structural assurance has a negative impact } \\
\text { on the Perceived environment risk in mobile services. }\end{array}$ & 0.02 & Rejected \\
\hline $\begin{array}{l}\text { H4a: Consume trust in mobile services has a positive } \\
\text { impact on the perceived usefulness of mobile services. }\end{array}$ & $0.14 * * *$ & Supported \\
\hline $\begin{array}{l}\text { H4b: Consume trust in mobile services has a positive } \\
\text { impact on the perceived ease of use of mobile services. }\end{array}$ & $0.29 * * *$ & Supported \\
\hline $\begin{array}{l}\text { H4c: Consume trust in mobile services has a positive } \\
\text { impact on the intention to use mobile services. }\end{array}$ & 0.09 & Rejected \\
\hline
\end{tabular}




\subsection{Structural Model and Hypotheses Testing}

The structural model was tested using Amos 20.0. The results of the structural model are shown in Figure. 2. The $R^{2}$ ( $R$ square) in Figure 2 denotes to coefficient of determination. It provides a measure of how well future outcomes are likely to be predicted by the model, the amount of variability of a given construct. In our analysis, the $\mathrm{R}^{2}$ coefficient of determination is a statistical measure of how well the regression coefficients approximate the real data point. The standardized path coefficients between constructs are presented, while the dotted lines stand for the non-significant paths. Table 3 presents the path coefficients, which are standardized regression coefficients. As a result, seven hypotheses were supported.

\section{Discussion}

In this research, we studied the acceptance of mobile services in China. And the role of trust played in this process was examined. This research was considered to be beneficial for academic research since it extends and enhances the understanding of adoption and mobile services in China. The findings demonstrated the appropriateness of the research model and hypotheses for measuring mobile services adoption.

The positive impact of perceived reputation on trust was significant. Among the numerous services, providers with good reputation can decrease the perceived vulnerability of users and a good impression based on previous experience can encourage the users to make an attempt to new services from the providers. This result is consistent with previous technology adoption studies in online shopping [22, 23]. For those providers with successful services before, they have more advantages in new services promotion than other market entrants.

The other factor, which has a positive influence on trust, was perceived structure assurance, which refers to mobile Internet and operating platform technologies here. Due to a safety structure assurance, users believed that they would not suffer attack and potential loss from hackers, and they would be compensated if that happened [2].

However, perceived environment risk does not have positive effect on consumers' trust in mobile services. According to the descriptive results, perceived environment risk has an average value of 5.13 on a seven point Likert scale. But the influence of perceived environment risk on users' trust was insignificant. The possible explanation might be that users are confidence with their qualified skills to avoid fraud services, and the mobile service has some schemes to protect users' security and privacy issues. Trust has both positive influence on perceived ease of use and perceived usefulness significantly.

Further, another interesting finding of this study was that trust did not have direct positive effect on the intention to use mobile services. This is contradictory with some previous research (e.g., $[1,24])$. As our research aimed to investigate users' adoption of general mobile services in China, the results may vary from a specific mobile service to another mobile service. The research results also confirmed the positive influence of perceived usefulness and perceived ease of use on the intention to use mobile services. It revealed the importance of ease of use and usefulness of mobile services toward users' adoption of mobile services. 
However, we were also aware of some limitations. Firstly, we only tested the research model and research hypotheses with general mobile services in China. Therefore, the generalizability of the results to a specific mobile service remains to be determined. Secondly, the subjects in this study were mainly university students. This sample may not be fully representative of the entire population in China.

\section{Conclusion and Future Research}

This research was designed to study the role of trust towards the adoption of mobile services in China. To our best knowledge, only a few studies were concerned with identifying trust-related factors that affect the adoption of mobile services in China. This study examined users' adoption with general mobile services by extending TAM with additional trust-related constructs. A research model with 10 research hypotheses was proposed in the study. Seven research hypotheses were positively significant supported, while three research hypotheses were rejected in this study. The results indicated that both perceived reputation and perceived structural assurance directly affects the consumers' trust in mobile services. But, consumers' trust in mobile services does not have direct positive effect on user's intention to use mobile services.

Continuing with this stream of research, we plan to examine the applicability of the research model with a specific mobile service, such as mobile information service or mobile payment. Future research is also needed to empirically verify the research model with larger samples across the world. Furthermore, some mediating factors (e.g., gender) may provide fresh insights and offer new directions for future research.

Acknowledgement. This research is supported by the Fundamental Research Funds for the Central Universities, China (Project No. ZNUFE. 2012065).

\section{References}

1. Ajzen, I.: The theory of planned behavior. Organizational Behavior and Human Decision Processes 50(2), 179-211 (1991)

2. Aldridge, A., White, M., Forcht, K.: Security considerations of doing business via the Internet: cautions to be considered. Internet Research 7(1), 9-15 (1997)

3. Bagozzi, R.P., Yi, Y.: On the evaluation of structural equation models. Journal of the Academy of Marketing Science 16(1), 74-94 (1988)

4. Bagozzi, R.P., Yi, Y.: Specification, evaluation, and interpretation of structural equation models. Journal of the Academy of Marketing Science 40(1), 8-34 (2012)

5. Bélanger, F., Carter, L.: Trust and risk in e-government adoption. The Journal of Strategic Information Systems 17(2), 165-176 (2008)

6. Benbasat, I., Barki, H.: Quo Vadis TAM. Journal of the Association for Information Systems 8(4), 211-218 (2007)

7. Bentler, P.M.: Comparative fit indexes in structural models. Psychological Bulletin 107(2), 238 (1990) 
8. Chandra, S., Srivastava, S.C., Theng, Y.-L.: Evaluating the role of trust in consumer adoption of mobile payment systems: An empirical analysis. Communications of the Association for Information Systems 27, 561-588 (2010)

9. Chen, L.-D.: A model of consumer acceptance of mobile payment. Int. J. Mob. Commun. 6(1), 32-52 (2008)

10. Dahlberg, T., Mallat, N., Ondrus, J., et al.: Past, present and future of mobile payments research: A literature review. Electronic Commerce Research and Applications 7(2), 165-181 (2008)

11. Davis, F.D.: Perceived usefulness, perceived ease of use and user acceptance of information technology. MIS Quarterly 13, 319-340 (1989)

12. Davis, F.D., Bagozzi, R.P., Warshaw, P.R.: User acceptance of computer technology: a comparison of two theoretical models. Manage. Sci. 35(8), 982-1003 (1989)

13. DeLone, W., McLean, E.: Information Systems Success: The Quest for the Dependent Variable. Information Systems Research 3 (1) (1992)

14. Doney, P.M., Cannon, J.P.: An Examination of the Nature of Trust in Buyer-Seller Relationships. Journal of Marketing 61(2), 35-51 (1997)

15. Fishbein, M., Ajzen, I.: Belief, Attitude, Intention and Behavior: An Introduction to Theory and Research. Addison-Wesley (1975)

16. Gao, S., Krogstie, J., Gransæther, P.A.: Mobile Services Acceptance Model. In: The Proceedings of International Conference on Convergence and Hybrid Information Technology. IEEE Computer Society (2008)

17. Gao, S., Krogstie, J., Siau, K.: Adoption of mobile information services: An empirical study. Mobile Information Systems 10(2), 147-171 (2014)

18. Gao, S., Krogstie, J., Siau, K.: Developing an instrument to measure the adoption of mobile services. Mobile Information Systems 7(1), 45-67 (2011)

19. Gao, S., Moe, S.P., Krogstie, J.: An empirical test of the mobile services acceptance model. In: 2010 Ninth International Conference on Mobile Business and 2010 Ninth Global Mobility Roundtable (ICMB-GMR), pp. 168-175. IEEE (2010)

20. Gao, S., Zang, Z., Gopalakrishnan, S.: A study on distribution methods of mobile applications in China. In: The Proceedings of Seventh International Conference on Digital Information Management (ICDIM), pp. 375-380. IEEE Computer Society (2012)

21. Gao, S., Zang, Z., Krogstie, J.: The Adoption of Mobile Games in China: An Empirical Study. In: Liu, K., Gulliver, S.R., Li, W., Yu, C., et al. (eds.) ICISO 2014. IFIP AICT, vol. 426, pp. 368-377. Springer, Heidelberg (2014)

22. Gefen, D.: TAM or Just Plain Habit: A Look at Experienced. Online Shoppers. Journal of End User Computing 15(3), 1-13 (2003)

23. Gefen, D., Karahanna, E., Straub, D.W.: Trust and TAM in Online Shopping: An Integrated Model. MIS Quarterly 27(1), 51-90 (2003)

24. Hayduk, L.A.: Structural equation modeling with LISREL: Essentials and advances. JHU Press (1988)

25. Hoffman, D.L., Novak, T.P., Peralta, M.: Building consumer trust online. Commun. ACM 42(4), 80-85 (1999)

26. Horton, R.P., Buck, T., Waterson, P.E., et al.: Explaining intranet use with the technology acceptance model. Journal of Information Technology 16, 237-249 (2001)

27. Legris, P., Ingham, J., Collerette, P.: Why do people use information technology?: a critical review of the technology acceptance model. Inf. Manage. 40(3), 191-204 (2003)

28. Luarn, P., Lin, H.-H.: Toward an understanding of the behavioral intention to use mobile banking. Computers in Human Behavior 21(6), 873-891 (2005) 
29. Mayer, R., Davis, J., Schoorman, D.: An Integrative Model of Organizational Trust. The Academy of Management Review 20(3), 709-734 (1995)

30. McKnight, D.H., Chervany, N.L.: What trust means in e-commerce customer relationships: an interdisciplinary conceptual typology. International Journal of Electronic Commerce 6, 35-60 (2002)

31. Moon, J.-W., Kim, Y.-G.: Extending the TAM for a World-Wide-Web context. Inf. Manage. 38(4), 217-230 (2001)

32. Pavlou, P.A.: Consumer Acceptance of Electronic Commerce: Integrating Trust and Risk with the Technology Acceptance Model. Int. J. Electron. Commerce 7(3), 101-134 (2003)

33. Rogers, E.M.: The diffusion of innovations. Free Press, New York (1995)

34. Scott, J.E.: The measurement of information systems effectiveness: evaluating a measuring instrument. ACM SIGMIS Database 26(1), 43-61 (1995)

35. Venkatesh, V., Morris, M.G., Davis, G.B., et al.: User Acceptance of Information Technology: Toward a Unified View. MIS Quarterly 27(3), 425-478 (2003)

36. von Watzdorf, S., Ippisch, T., Skorna, A., et al.: The Influence of Provider Trust on the Acceptance of Mobile Applications: An Empirical Analysis of Two Mobile Emergency Applications. In: 2010 Ninth International Conference on Mobile Business (ICMB-GMR), pp. 329-336 (2010)

37. Wu, J.-H., Wang, S.-C.: What drives mobile commerce? An empirical evaluation of the revised technology acceptance model. Inf. Manage. 42(5), 719-729 (2005)

38. Yang, K.C.C.: Exploring factors affecting the adoption of mobile commerce in Singapore. Telemat. Inf. 22(3), 257-277 (2005)

39. Zucker, L.G.: Production of trust: Institutional sources of economic structure, 1840-1920. Research in Organizational Behavior (1986) 